\section{(6) OPEN ACCESS}

\title{
Quality of advance care planning policy and practice in residential aged care facilities in Australia
}

\author{
William Silvester, ${ }^{1}$ Rachael S Fullam, ${ }^{1}$ Ruth A Parslow, ${ }^{2}$ Virginia J Lewis, ${ }^{2}$ \\ Rebekah Sjanta, ${ }^{1}$ Lynne Jackson, ${ }^{1}$ Vanessa White, ${ }^{2}$ Jane Gilchrist ${ }^{1}$
}

\begin{abstract}
- Additional tables are published online only. To view these files please visit the journal online (http://dx.doi.org/ 10.1136/bmjspcare-2012000262).

\section{${ }^{1}$ Respecting Patient Choices, Austin Health, Heidelberg, Victoria, Australia \\ ${ }^{2}$ Australian Institute for Primary Care and Ageing, La Trobe University, Melbourne, Victoria, Australia}

\section{Correspondence to}

Dr Rachael S Fullam, Respecting Patient Choices, Austin Hospital PO Box 5555, Heidelberg, VIC 3084, Australia; rachael.fullam@austin.org.au

Accepted 7 August 2012 Published Online First 14 November 2012

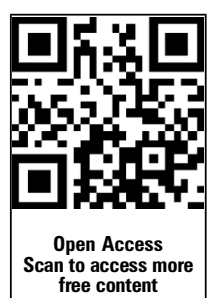

To cite: Silvester $W$, Fullam RS, Parslow RA, et al. BMJ Supportive \& Palliative Care 2013;3:349-357.

\section{ABSTRACT}

Objectives To assess existing advance care planning (ACP) practices in residential aged care facilities (RACFs) in Victoria, Australia before a systematic intervention; to assess RACF staff experience, understanding of and attitudes towards ACP.

Design Surveys of participating organisations concerning ACP-related policies and procedures, review of existing ACP-related documentation, and pre-intervention survey of RACF staff covering their role, experiences and attitudes towards ACP-related procedures.

Setting 19 selected RACFs in Victoria. Participants 12 aged care organisations (representing 19 RACFs) who provided existing ACP-related documentation for review, 12 RACFs who completed an organisational survey and 45 staff (from 19 RACFs) who completed a pre-intervention survey of knowledge, attitudes and behaviour.

Results Findings suggested that some ACPrelated practices were already occurring in RACFs; however, these activities were inconsistent and variable in quality. Six of the 12 responding RACFs had written policies and procedures for ACP; however, none of the ACP-related documents submitted covered all information required to meet ACP best practice. Surveyed staff had limited experience of ACP, and discrepancies between self reported comfort, and levels of knowledge and confidence to undertake ACP-related activities, indicated a need for training and ongoing organisational support.

Conclusions Surveyed organisationsâ policies and procedures related to ACP were limited and the quality of existing documentation was poor. RACF staff had relatively limited experience in developing advance care plans with facility residents, although attitudes were positive. A systematic approach to the implementation of $A C P$ in residential aged care settings is required to ensure best practice is implemented and sustained.

It is widely acknowledged that the application of advance care planning (ACP) is an important component of personalised end-of-life care, and that recognition and accommodation of preferences expressed in ACP documents allow individuals to have control over the level of health care they receive at the end of life. ${ }^{1-5}$ Studies conducted in different healthcare settings suggest that ACP can improve patient and family satisfaction with care, ${ }^{6} 7$ reduce nursing home to hospital transfers, ${ }^{8-10}$ limit the application of burdensome treatments at the end of life in line with patient preferences, ${ }^{7} 1112$ and reduce indicators of stress, anxiety and depression in surviving relatives. ${ }^{6} 7$

Effective ACP requires that a number of key processes are undertaken and revised as necessary through ongoing practitioner-patient negotiations. These processes include: (i) consideration of options and expression of values; (ii) communication and documentation of preferences; (iii) identification, where possible, of a surrogate decision maker able to make decisions for treatment when these preferences and decisions cannot be made by the patient; and (iv) ensuring that such documentation is made available to practitioners across different healthcare settings, for example when the patient moves from an aged care facility to hospital. ${ }^{3} 13-15$

Initiation of discussions leading to the completion of advance directives (ADs) is dependent on the individual policies and priorities of health managers and practitioners. $^{16}{ }^{17}$ However, the impact of legislation supporting $\mathrm{ADs}$ is questionable 
even when it is enacted nationally. After the Patient Self-Determination Act was implemented in the USA in $1991,{ }^{18}$ higher proportions of some patient populations completed $\mathrm{ADs}$, in at least some healthcare settings. ${ }^{19-22}$ Despite this improvement in uptake, studies have indicated that there is considerable variability in the concordance between previously expressed treatment preferences and actual treatment provision. ${ }^{11}{ }^{23-26}$ Organisational policies, procedures and systems are required to reinforce and support good practice.

In Australia, legislation underwriting ADs exists in most but not all states and territories. The legislation varies in terminology, intent and associated physician liability. ${ }^{27} 28$ A number of studies have examined aspects of ACP in Australia, including guidelines for implementing ACP in Australian healthcare settings, ${ }^{1} 42930$ the roles of different health practitioners in supporting $\mathrm{ACP},{ }^{31-34}$ and the outcomes of a randomised controlled trial in which elderly patients were allocated to receive usual care or facilitated ACP. ${ }^{6}$ In the specific context of Australian residential aged care facilities (RACFs), development of advance care plans may or may not be part of the institution's policy, and in those settings where the importance of the ACP process is recognised, the quality of processes and instruments developed has been found to be variable and often question-

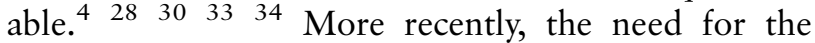
provision of quality ACP within Australian residential aged care settings has been highlighted during major healthcare reviews ${ }^{35}$ and in federal strategies. ${ }^{36}$ Given these developments, ACP provision within RACFs may have become more extensive and of better quality, although there are no recent studies specifically examining this issue.

The federally funded Respecting Patient Choices (RPC) programme completed the previously noted randomised controlled trial in Melbourne, Australia $^{6}$ and is now completing a major related project 'Making Health Choices' (MHC) which aims to develop, trial and evaluate a sustainable model for implementing ACP in RACFs in Australia. Participating RACFs had not previously received formal ACP training from the RPC programme. The pre-implementation evaluation involved detailed examination of ACP policy and practice within facilities, and staff knowledge, attitudes and behaviours in relation to ACP. This paper presents the key findings of the pre-implementation evaluation; post-implementation changes to these findings will be reported in a future paper. We hypothesised that although pre-implementation ACP awareness and practice within the project facilities may be higher than previously reported, in line with previous research in this area, ${ }^{4} 28303334$ the quality of ACP practices would be highly variable.

\section{METHODS}

All surveys were developed from instruments utilised in a previous ACP implementation study involving 19 RACFs and 187 staff. $^{37}$ The present evaluation was also informed by best practice principles for ACP in the aged care setting (see box 1 for an overview), formulated by a working group consisting of industry experts in aged and palliative care, academics and RPC staff.

At the beginning of the MHC project, two geographical regions of the state of Victoria, the first in the state's capital and the second in a rural area, were targeted due to a lack of previous RPC ACP implementation in these regions. Information regarding the project was distributed to 51 aged care organisations (representing 93 RACFs) operating within these regions. Organisations that attended a subsequent information session were invited to submit an expression of interest for inclusion in the MHC project. Expressions of interest required a commitment to the

Box 1 An overview of best practice advance care planning (ACP) in residential aged care facilities

- Facilities have written policies and procedures about ACP that are readily accessible and establish ACP as a routine component of care.

- Regular ACP education is provided to aged care service staff, residents and relatives, and general practitioners (GPs).

- Residents and families are given information regarding ACP before or at admission.

- ACP is offered to residents within 28 days of admission.

- ACP is completed by an appropriately skilled health professional during an in-depth discussion with the older person and/or their family.

- The focus of the ACP conversation is on reasonable outcomes and 'living well'. The conversation raises the issues of life-prolonging treatment generally but does not focus on any specific treatment.

- GPs are involved in ACP discussions.

- Completed advance care plans are regularly reviewed.

- ACP documents clearly specify (at a minimum): (a) a nominated substitute decision maker (and contact details) where applicable; (b) current state of health; (c) values and beliefs (things that matter most in life); (d) future unacceptable health conditions; (e) level of preferred future medical treatment indicated; (f) specific wanted/unwanted treatments, where applicable; (g) goals for end-of-life care; and (h) appropriate signatures (clear, complete, dated, witnessed), and include evidence of GP review.

- Facilities have effective information transfer systems in place to enable communication of resident ACP information across health transition points. 
project deliverables from the organisation's executive, an assessment of organisational preparedness and agreement to contribute to ongoing data collection via on-line surveys. Organisations were asked to nominate no more than four RACFs for inclusion in the project. Thirteen aged care organisations (eight metropolitan and five regional, representing 20 RACFs) submitted an expression of interest and all were included in the project. Due to a change of management, one organisation (representing one RACF) subsequently withdrew from the project prior to the start of the education phase. The final project sample comprised 11 metropolitan RACFs (operated by seven aged care organisations) and eight rural RACFs (operated by five organisations). Participating organisations were asked to nominate staff members to attend MHC education programmes. Organisations were specifically requested to nominate both management and senior clinical staff to participate. This strategy was employed in order to support sustainable implementation of ACP during the MHC project.

\section{Data collection}

Evaluation of the MHC project was approved by La Trobe University Human Research Ethics Committee. Organisation and facility level consent for inclusion in the project was obtained during the expression of interest process. Individual consent for inclusion in the pre-implementation evaluation was implicit with the completion of survey instruments.

\section{Facility level data}

General information about each participating RACF was collected from the Australian Department of Health and Ageing Aged Care Summary Data and Service list. ${ }^{i}$ Information was sought on ownership (eg, government, not for profit, private), number of beds and care level. Managers of participating RACFs were asked to complete online resident profile surveys. Information collected included primary reasons for admission of residents, age range of residents and number of resident deaths during the previous financial year. Each RACF manager was also asked to participate in an online pre-implementation survey regarding the organisation's written policies and procedures around ACP, whether ACP practice within each area was routinely audited, and the extent to which ACP discussions covered key domains including discussion of residents' medical treatment options, wishes around hospital transfer, and residents' goals and values. They were also asked to provide copies of any existing ACP-related documentation used to record resident treatment preferences and end-of-life wishes prior to the MHC project. This pre-existing

${ }^{i}$ http://www.health.gov.au/internet/main/publishing.nsf/Content/ ageing-rescare-servlist-download.htm documentation was reviewed by the MHC project team. The surveys remained open for a period of 1 month before commencement of the education phase of the MHC project.

\section{Staff level data}

Staff nominated by their aged care organisations to participate in the MHC project were asked to respond to an online pre-implementation survey which included questions about their sociodemographic attributes, current professional position or classification, years of experience and time fraction worked, their understanding and knowledge of ACP, the application of ACP in RACF settings generally and their workplace specifically, and their experience of facilitating ACP with residents. All respondents were advised that no personally identifying information would be kept with survey responses. The survey remained open for a period of 1 month prior to the start of the education phase of the MHC project.

\section{Data analysis}

The data analysis was largely descriptive. Small sample sizes precluded statistical comparison of data according to facility level variables. Limited comparisons based on individual level variables were made for the staff survey data using Mann-Whitney U tests.

\section{RESULTS}

Facility data for the 19 participating RACFs are given in table 1. Resident profile data were obtained from 10 of these RACFs. Several RACF managers did not complete this survey due to workload pressures. All responder and non-responder RACFs provided high

Table 1 Profiles of participating residential aged care facilities

\begin{tabular}{|c|c|c|c|}
\hline & $\begin{array}{l}\text { Provided } \\
\text { resident profile } \\
\text { information } \\
(n=10)\end{array}$ & $\begin{array}{l}\text { Did not provide } \\
\text { resident profile } \\
\text { information } \\
(n=9)\end{array}$ & $\begin{array}{l}\text { Total } \\
(\mathrm{n}=19)\end{array}$ \\
\hline \multicolumn{4}{|l|}{ Organisation type } \\
\hline State government & 5 & 4 & 9 \\
\hline Not for profit & 4 & 3 & 7 \\
\hline Private, for profit & 1 & 2 & 3 \\
\hline \multicolumn{4}{|l|}{ Located in } \\
\hline Metropolitan area & 4 & 7 & 11 \\
\hline Inner regional area & 6 & 2 & 8 \\
\hline \multicolumn{4}{|l|}{ Number of beds } \\
\hline $1-50$ & 3 & 4 & 7 \\
\hline $51-100$ & 4 & 5 & 9 \\
\hline Over 100 & 3 & 0 & 3 \\
\hline \multicolumn{4}{|l|}{ Care level } \\
\hline $\begin{array}{l}\text { Low care with } \\
\text { aging-in-place }\end{array}$ & 6 & 1 & 7 \\
\hline Low and high care & 3 & 2 & 5 \\
\hline High care & 1 & 6 & 7 \\
\hline
\end{tabular}


care (care for residents who may have complex healthcare needs and/or who may require increased support for activities of daily living and/or behavioural management). This was either as the majority of care provided (high-care only facilities), in a separate unit alongside a low-care unit (low and high care) or as part of an aging-in-place facility (high care provided in situ as residents' needs increase). However, there were more high-care only facilities in the nonresponder sample. In addition, there were no RACFs with over 100 beds in the non-responder sample.

Resident profile data are provided in table 2. Over $70 \%$ of residents admitted during the period studied were 80 or more years old. The primary reason for admission was given as frailty in $60 \%$ of cases, with dementia indicated in $30 \%$ of cases. It should be noted that collecting data on the primary reason for admission will not measure actual rates of dementia in participant RACFs as residents often have multiple comorbid conditions on admission. However, the admission profile may also reflect the greater number of facilities providing low care in the responder sample.

The survey of current ACP policies and procedures was completed by the managers of 12 of the 19 RACFs. The responder sample had a lower proportion of facilities funded to provide high care only, and a higher proportion of facilities with 100 or more beds (see online supplementary table S1 for a description of the characteristics of responding and nonresponding facilities). The 12 RACFs reported written policies and auditing in the following domains: ACP —six with policies, four conducting audits; end-of-life

Table 2 Participating facility resident profile information for 1 July 2009 to 30 June $2010(n=10)$

\begin{tabular}{lcccc}
\hline & Total & Median & Minimum & Maximum \\
\hline Number of beds & 766 & 67.5 & 44 & 127 \\
$\begin{array}{l}\text { Average length of stay } \\
\text { (months) }\end{array}$ & - & 31.0 & 2 & 76.8 \\
Total permanent resident & 198 & 14.0 & 0 & 46.0 \\
deaths/year & & & & \\
Permanent resident & 252 & 21.5 & 11 & 50 \\
admissions/year & & & & \\
Admissions/year & 154 & 13 & 0 & 41 \\
Frail & 59 & 4 & 0 & 21 \\
Dementia & 15 & 0.5 & 0 & 5 \\
Palliative & 27 & 1 & 0 & 11 \\
Social & 2 & 0 & 0 & 2 \\
ABI & 5 & 0.5 & 0 & 1 \\
50-59 years old & 11 & 1 & 0 & 3 \\
$60-69$ years old & 51 & 4.5 & 2 & 9 \\
$70-79$ years old & 126 & 11 & 3 & 21 \\
80-89 years old & 62 & 4 & 0 & \\
$90+$ years old & & & & \\
\hline
\end{tabular}

Disparities between the reported total admissions per year and the reported totals for admission by primary reason and by age are due to responder inaccuracy when completing the resident profile survey. $A B I$, acquired brain injury. care-eight with policies, eight conducting audits; palliative care-12 with policies, nine conducting audits; resuscitation-six with policies, four conducting audits; consent to treatment-eight with policies, five conducting audits; and substitute decision makerssix with policies, zero conducting audits. Table 3 provides information about how and when ACP information was given to residents, when ACP documents would be completed, and what kinds of information were discussed. Only four of 12 respondents to the organisational survey expressed the view that ACP information was used effectively in their facility.

Reviews of existing ACP-related documentation indicated that participating aged care organisations used a variety of documents to record residents' treatment preferences and end-of-life wishes. Overall, none of the 12 pre-intervention documents submitted for review (representing documents used in all

Table 3 Current ACP practices reported by respondents to the organisational survey

\begin{tabular}{|c|c|}
\hline ACP practice item & $\begin{array}{l}\text { Number offacilities } \\
(\mathrm{n}=12)\end{array}$ \\
\hline \multicolumn{2}{|l|}{ Provision of ACP information to residents } \\
\hline No ACP information given & 1 \\
\hline On admission & 2 \\
\hline After admission & 5 \\
\hline On admission and after admission & 2 \\
\hline $\begin{array}{l}\text { Before admission, on admission and after } \\
\text { admission }\end{array}$ & 2 \\
\hline \multicolumn{2}{|l|}{ Extent of ACP completion } \\
\hline All permanent residents* & 7 \\
\hline $\begin{array}{l}\text { Some permanent residents with no particular } \\
\text { rationale }\end{array}$ & 5 \\
\hline $\begin{array}{l}\text { Some permanent residents who meet specific } \\
\text { criteria }\end{array}$ & 0 \\
\hline \multicolumn{2}{|l|}{ Time to advance care plan completion } \\
\hline Within the 1st month of admission & 6 \\
\hline Within the 2nd month of admission & 4 \\
\hline On resident/family request only & 2 \\
\hline \multicolumn{2}{|l|}{ Information collected/discussed } \\
\hline $\begin{array}{l}\text { Appointment of an SDM (MEPOA)/ } \\
\text { guardianshipt }\end{array}$ & 9 \\
\hline Residents' palliative care wishes & 10 \\
\hline Residents' pain management guidelines & 2 \\
\hline $\begin{array}{l}\text { Residents' wishes around hospital transfer in } \\
\text { the eventof illness }\end{array}$ & 11 \\
\hline Residents' medical treatment options & 5 \\
\hline Residents' end-of-life wishes & 10 \\
\hline Residents' funeral wishes & 10 \\
\hline $\begin{array}{l}\text { The things that matter most to the resident } \\
\text { about living and their end of life }\end{array}$ & 1 \\
\hline \multicolumn{2}{|c|}{$\begin{array}{l}\text { *Permanent resident, excludes residents who are briefly admitted for } \\
\text { respite care. } \\
\text { †Guardianship: appointment of a person to make decisions for an adult } \\
\text { with a disability when they are unable to do so. } \\
\text { ACP, advance care planning; MEPOA, medical enduring power of attorney; } \\
\text { SDM, substitute decision maker. }\end{array}$} \\
\hline
\end{tabular}


participating RACFs) adequately covered all information domains seen as essential and required for effective, best practice ACP. ${ }^{30}{ }^{38}$ Document sets were most likely to include sections related to information about personal/cultural/religious wishes in relation to end-of-life care (questions such as 'Are there any special fulfilling requests or wishes that the resident or family wishes to achieve prior to death'), residents' preferences as regards hospital transfer and a signature section. A future paper will report in more detail on the limitations of existing ACP documentation and consequent recommendations for best practice.

Sixty-five of the 71 RACF staff participants commenced the pre-implementation staff survey. Eight who failed to complete the survey and 11 respondents who completed the survey after they had undertaken online e-learning components of the MHC project training were excluded. Another individual's survey was excluded because her organisation withdrew from the programme. Sociodemographic and employment information provided by the 45 staff who completed the survey is given in table 4 . The majority of staff were over 50 years old, had tertiary qualifications, worked full time, had practiced in aged care for 15 years or more, and were registered nurses or managers. Table 5 details the responses provided by participants concerning their previous experience with ACP-related discussions. Overall, the majority of participants had had little or no experience in holding such discussions. Those who had had such discussions or knew of these processes being conducted in their RACF reported that they or other staff members were most likely to initiate such conversations (table 5). The majority of respondents indicated that they were 'comfortable' or 'very comfortable' having discussions around ACP, wishes in the event of a deterioration of health and/or end-of-life care. Fewer reported that they felt 'skilled' or 'very skilled' to have such discussions. Levels of confidence reported to undertake the different tasks and activities associated with ACP varied, with the majority of respondents reporting they felt 'not at all confident' or 'a little confident' in relation to most specified activities, including knowing the role of the substitute decision maker, knowing the relevant laws, teaching other healthcare providers about ACP, or mediating when there is a disagreement between the resident and family regarding end-of-life care (see online supplementary table S2 for detailed item responses).

Participant knowledge of ACP was assessed by marking seven statements as true or false. Forty-four per cent of respondents answered four of the questions correctly, with a further $27 \%$ answering five questions correctly. However, one statement 'People may appoint anyone they wish as a substitute decision maker' was incorrectly classified as true by over $70 \%$ of respondents. Two further statements (both false): 'People must have both a written advance care plan
Table 4 Characteristics of the 45 participants who completed the pre-implementation staff survey

\begin{tabular}{|c|c|}
\hline Attribute & Number (\%) \\
\hline \multicolumn{2}{|l|}{ Age range (years) } \\
\hline $20-29$ & $1(2.2)$ \\
\hline $30-39$ & $7(15.6)$ \\
\hline $40-49$ & $13(28.9)$ \\
\hline $50-59$ & $21(46.7)$ \\
\hline 60 or over & $3(6.7)$ \\
\hline \multicolumn{2}{|l|}{ Highest educational qualification } \\
\hline Certificate/diploma & $18(40.0)$ \\
\hline Undergraduate degree & $6(13.3)$ \\
\hline Graduate diploma/honours & $14(31.1)$ \\
\hline Master's degree & $7(15.6)$ \\
\hline \multicolumn{2}{|l|}{ Time fraction currently worked } \\
\hline Full-time & $25(55.6)$ \\
\hline Part-time (0.5-0.9 equivalent full-time) & $17(37.8)$ \\
\hline Part-time (0.1-0.5 equivalent full-time) & $3(6.7)$ \\
\hline \multicolumn{2}{|l|}{ Current position/classification } \\
\hline Registered nurse division 1 & $10(22.2)$ \\
\hline Registered nurse division 2, or senior enrolled nurse & $7(15.5)$ \\
\hline Care coordinator/supervisor & $6(13.3)$ \\
\hline Service manager & $11(24.4)$ \\
\hline Executive officer & $3(6.7)$ \\
\hline Director of care/nursing & $2(4.4)$ \\
\hline Quality manager & $4(8.9)$ \\
\hline Other & $2(4.4)$ \\
\hline \multicolumn{2}{|l|}{ Years practised in current workplace } \\
\hline $0-4$ & $24(53.3)$ \\
\hline $5-9$ & $9(20.0)$ \\
\hline $10-14$ & $5(11.1)$ \\
\hline $15-19$ & $3(6.7)$ \\
\hline 20 or over & $4(8.9)$ \\
\hline \multicolumn{2}{|l|}{ Years practised in aged care } \\
\hline $0-4$ & $6(13.3)$ \\
\hline $5-9$ & $6(13.3)$ \\
\hline $10-14$ & $6(13.3)$ \\
\hline $15-19$ & $12(26.7)$ \\
\hline 20 or over & $15(33.3)$ \\
\hline
\end{tabular}

and a substitute decision maker before end-of-life decisions are honoured' and 'If a resident lacks decision-making capacity and does not have a substitute decision maker, healthcare providers must seek legal permission to stop life-sustaining treatment', were incorrectly assessed as true by almost half of participants (see online supplementary table S3). There were no significant differences in total ACP general knowledge score when the sample was split and compared by age, years of aged care experience, or educational qualification level (see online supplementary table S4).

Respondents to the staff survey indicated the extent to which they agreed or disagreed with a number of attitudinal statements concerning ACP and end-of-life 
Table 5 Staff survey respondents' experience, comfort and skill in dealing with ACP discussions

\begin{tabular}{|c|c|c|c|c|}
\hline & \multicolumn{4}{|c|}{ Number (\%) who had discussions with } \\
\hline & $\begin{array}{l}\text { Most/all } \\
\text { residents }\end{array}$ & $\begin{array}{l}\text { Some } \\
\text { residents }\end{array}$ & $\begin{array}{l}\text { Very few/no } \\
\text { residents }\end{array}$ & $\begin{array}{l}\text { Have had no } \\
\text { discussions }\end{array}$ \\
\hline \multicolumn{5}{|c|}{ Respondents reporting that, in the past 6 months, they had discussions with residents about } \\
\hline ACP & $3(6.6)$ & $8(17.8)$ & $18(40.0)$ & $16(35.8)$ \\
\hline Residents' wishes in the event of deterioration of health & $4(8.9)$ & $6(13.3)$ & $35(46.7)$ & $14(31.1)$ \\
\hline \multirow[t]{2}{*}{ End-of-life care } & $1(2.2)$ & $8(17.8)$ & $36(44.4)$ & $16(35.6)$ \\
\hline & & & \multicolumn{2}{|c|}{ Number (\%) } \\
\hline \multicolumn{3}{|c|}{ Discussions about $A C P$, deterioration of health/end-of-life care usually initiated by } & \multicolumn{2}{|c|}{$\mathrm{n}=45$} \\
\hline \multicolumn{3}{|l|}{ Self or other staff } & \multicolumn{2}{|c|}{$30(66.7)$} \\
\hline \multicolumn{3}{|l|}{ Family or friends of resident } & \multicolumn{2}{|c|}{$5(11.1)$} \\
\hline \multicolumn{3}{|l|}{ Resident } & \multicolumn{2}{|c|}{$0(0.0)$} \\
\hline \multicolumn{3}{|l|}{ Other or no discussions occurred } & \multicolumn{2}{|c|}{$10(22.2)$} \\
\hline \multicolumn{3}{|c|}{ Level of comfort dealing with discussions around $A C P$, deterioration of health/end-of-life care } & \multicolumn{2}{|c|}{$\mathrm{n}=41$} \\
\hline \multicolumn{3}{|l|}{ Comfortable or very comfortable } & \multicolumn{2}{|c|}{$27(65.9)$} \\
\hline \multicolumn{3}{|l|}{ Neither comfortable nor uncomfortable } & \multicolumn{2}{|c|}{$8(19.5)$} \\
\hline \multicolumn{3}{|l|}{ Uncomfortable or very uncomfortable } & \multicolumn{2}{|c|}{$6(14.6)$} \\
\hline \multicolumn{3}{|c|}{ Self-perceived skill in dealing with discussions around ACP, deterioration of health/end-of-life care } & \multicolumn{2}{|c|}{$\mathrm{n}=42$} \\
\hline \multicolumn{3}{|l|}{ Skilled or very skilled } & \multicolumn{2}{|c|}{$21(50.0)$} \\
\hline \multicolumn{3}{|l|}{ Neither skilled nor unskilled } & \multicolumn{2}{|c|}{$16(38.1)$} \\
\hline \multicolumn{3}{|l|}{ Unskilled or very unskilled } & \multicolumn{2}{|c|}{$5(11.9)$} \\
\hline
\end{tabular}

ACP, advance care planning.

care (see online supplementary table S5). Responses to these statements suggested that participants valued and supported ACP, recognised the importance of documenting the wishes and preferences of residents, and considered that priority should be given to such documented preferences over relatives' wishes and standard medical protocols.

The 45 staff respondents were also asked about organisational policies and procedures within the RACF. Only 16 (35.6\%) reported that their service had policies and procedures concerning ACP; 14 of these 16 respondents had read those documents. Twenty-three respondents $(51.1 \%)$ reported that their service had no such procedures in place, while the six remaining participants $(13.3 \%)$ did not know whether or not such policies and procedures existed in their service. Responses to questions concerning actual and documented procedures for recording ACP discussions are given in table 6. Approximately half of the respondents (53\%) said that ACP was implemented 'poorly' or 'very poorly' within their RACF.

When respondents were asked about their recognition of and compliance with advance care plans in the past, 71\% indicated they would trust ('quite a bit'/ 'very much') the information recorded about a resident's advance care and/or end-of-life wishes, and $74 \%$ said they would use the information recorded in a resident's ACP to guide the treatment and care that they provided ('quite a bit'/'very much'). Sixteen of the 45 respondents said they had cared for a resident with an ACP in the past 6 months. Five respondents said that in the past 6 months they had provided treatment to a resident who had previously indicated that

Table 6 Current procedures and practices around advanced care planning $(A C P)$ in residential aged care facilities as reported by staff survey respondents

\begin{tabular}{ll}
\hline $\begin{array}{l}\text { Actions taken when a resident/family } \\
\text { member raises ACP issues }\end{array}$ & $\begin{array}{l}\% \text { Usually taking } \\
\text { this action* }\end{array}$ \\
\hline Tell & \\
Senior nursing staff & 54.5 \\
Resident's GP & 65.6 \\
Another family member & 24.1 \\
Formally document discussions & 78.6 \\
Don't know what to do & 3.8 \\
Documentation of ACP discussions in facility & $\%$ Endorsing this \\
& $0 p$ tion* \\
Not documented & 12.0 \\
Recorded in & \\
Clinical notes by nursing staff & 97.1 \\
Clinical notes by GP & 84.8 \\
Clinical notes by allied health staff & 50.0 \\
Resident care plan & 79.3 \\
'Not for resuscitation' form & 97.2 \\
End-of-life care/palliative care plan & 94.1 \\
A specific ACP form & 41.4 \\
Admission documentation & 65.5 \\
\hline
\end{tabular}

*Percentages calculated from those responding to question. $\mathrm{GP}$, general practitioner. 
they did not want that treatment and six said they had observed others providing treatment to a resident who had previously indicated that they did not want that treatment.

\section{DISCUSSION}

This paper summarises findings from a preimplementation evaluation of 19 RACFs and selected staff participating in the MHC project. Current policies, procedures and practices around $\mathrm{ACP}$ were explored in 12 RACFs who completed the relevant survey. It also provides a brief overview of the results of a review of the contents and quality of existing ACP-related documentation in use at all participating facilities. It covers in detail the level of awareness, knowledge and practice related to ACP reported by 45 staff members working in a range of nursing and administrative positions within participating RACFs.

Overall, the findings from these surveys and documentation review suggest that some ACP-related practices were already occurring within facilities prior to the start of the MHC project, but that such activities were variable and lacked key components fundamental for best practice (see box 1). While these facilities were targeted because they had not previously received formal RPC training, some organisations had developed local practices relevant to ACP, a finding also reported previously. ${ }^{37}$ Although conclusions to be drawn from the available survey data are limited by small sample sizes, there is evidence of deficits in ACP practice in facilities prior to the implementation of the MHC project. For example, only half of the facilities reported having an ACP-specific policy at pre-implementation and none of the existing documentation submitted by participating RACFs adequately covered all domains required for best practice. These findings are also in line with other Australian studies. ${ }^{4} 2830333439$

Only a quarter of staff participants reported having discussed ACP with at least some RACF residents within the last 6 months. Fewer participants had specifically addressed issues such as residents' wishes in the event of deterioration in health or their end-of-life care. Given this limited experience, the validity of participants' self-reported comfort and skill in holding such discussions might be queried, and the apparent discrepancy between higher self-rated levels of comfort, but limited ACP knowledge and lower ratings of skill and confidence, understood. Staff attitudes were supportive of ACP, even where knowledge was sometimes weak. These results indicate a readiness to receive and implement ACP training in RACF staff. The majority of staff reported that few ACP discussions were initiated by the residents or their family, further reinforcing the need for staff to have the skills and confidence to initiate ACP discussions. The latter finding may reflect the residents' unwillingness to consider the issue (possibly underpinned by cognitive impairment), ${ }^{40}$ but may also reflect limited provision of information to residents regarding the opportunity to engage in ACP. The ineffectiveness of an ad hoc approach to ACP is reflected in the disparity between the apparent existence of ACP and end-of-life care policies and the self-reported low incidence of ACP discussions and documentation, and the 'poor' or 'very poor' implementation of ACP in these facilities.

The results of this study highlight the need to have a systematic approach to the implementation of ACP in RACFs for sustainable ongoing good practice. Interventions need to address existing shortcomings in organisational and staff capacity to ensure effective provision of ACP. In particular, ACP implementation has to address a major practical dilemma experienced by healthcare professionals in aligning philosophical views concerning the role and importance of ACP with making clinical treatment decisions that conflict with the preferences expressed in advance care plans. In the current pre-implementation data, while close to $80 \%$ of respondents reported that they would formally document ACP issues (only 41\% indicated that a specific ACP form was used to achieve this), almost 30\% expressed limited trust in the validity of such recorded information, while around one in four would not consistently use this information to guide treatment choices. Similarly, while a large majority of respondents considered a healthcare provider should not overrule an ACP when they disagreed with it, some two thirds of respondents felt it was not a nurse's responsibility to flag this conflict with the medical practitioner when it occurred. A systematic approach to ACP training and sustainable organisational implementation is required to ensure that the quality of ACP in RACFs and other settings is improved.

We recognise that the research has a number of limitations. The number of RACFs who responded to the pre-implementation survey of policies and practice was small, and represented $63 \%$ of facilities participating in the trial. This response rate and the response rate for provision of resident profile information is most likely a reflection of the extensive data collection required and is not thought to indicate a lack of enthusiasm by participating facilities. In line with this, all participating aged care organisations provided current RACF ACP documentation for quality review. The number of training participants who responded to the pre-implementation survey is relatively small although drawn from a number of different RACF settings. Although the study only involved RACFs in one Australian state, it represented a broad mixture of RACFs, metropolitan and rural, public and private, and may be a reasonable representation of ACP practice in Australian RACFs.

\section{CONCLUSION}

Overall, the findings from these surveys and documentation review suggest that some ACP-related 
practices were already occurring within facilities that had not previously been exposed to RPC initiatives specific to this topic. Nonetheless, there is evidence that existing ACP practices in facilities had pronounced deficits and that surveyed RACF staff had limited experience in discussing and documenting ACP with residents, and reported poor implementation of ACP in their facilities. Initiatives providing guidelines and education concerning ACP best practice are required to ensure that such documents are prepared for all residents who wish to engage in ACP, are comprehensive and are routinely used to inform health choices at end of life.

Acknowledgements We would like to thank all participating aged care organisations and associated residential aged care facilities and staff.

Contributors WS: project lead; RSF \& RAP: data analysis; VJL: study design. All authors contributed to the first draft and revisions.

Funding The Australian Government Department of Health and Ageing, National Palliative Care Program funded this study.

\section{Competing interests None.}

Ethics approval La Trobe University Human Research Ethics Committee approved evaluation of the MHC project.

Provenance and peer review Not commissioned; externally peer reviewed.

Open Access This is an Open Access article distributed in accordance with the Creative Commons Attribution Non Commercial (CC BY-NC 3.0) license, which permits others to distribute, remix, adapt, build upon this work non-commercially, and license their derivative works on different terms, provided the original work is properly cited and the use is non-commercial. See: http://creativecommons.org/licenses/by-nc/3.0/

\section{REFERENCES}

1 Jeong SY, Higgins I, McMillan M. The essentials of Advance Care Planning for end-of-life care for older people. J Clin Nurs 2010;19:389-97.

2 Alfonso $\mathrm{H}$. The importance of living wills and advance directives. J Geront Nurs 2009;35:42-5.

3 Cantor MD, Pearlman RA. Advance care planning in long-term facilities. J Am Dir Assoc 2004;5(2 Suppl):S72-80.

4 Nair B, Kerridge I, Dobson A, et al. Advance care planning in residential care. Aus NZ J Med 2000;30:339-43.

5 Blackford J, Strickland E, Morris B. Advance care planning in residential aged care facilities. Contemp Nurse 2007;27: 141-51.

6 Detering KM, Hancock AD, Reade MC, et al. The impact of advance care planning on end of life care in elderly patients: randomised controlled trial. BMJ 2010;340:1345.

7 Wright AA, Zhang B, Ray A, et al. Associations between End-of-life discussions, patient mental health, medical care near death, and caregiver bereavement adjustment. J Am Med Dir Assoc 2008;300:1665-73.

8 Caplan GA, Meller A, Squires B, et al. Advance care planning and hospital in the nursing home. Age Ageing 2006;35: 581-5.

9 Teno JM, Gozalo P, Mitchell SL, et al. Terminal hospitalizations of nursing home residents: does facility increasing the rate of do not resuscitate orders reduce them? J Pain Symptom Manage 2011;41:1040-7.
10 Badger F, Clifford C, Hewison A, et al. An evaluation of the implementation of a programme to improve end-of-life care in nursing homes. Palliat Med 2009;23: 502-11.

11 Hickman SE, Nelson CA, Moss AH, et al. The consistency between treatments provided to nursing facility residents and orders on the physician orders for life-sustaining treatment form. J Am Geriatr Soc 2011;59:2091-9.

12 Monturo CA, Strumpf NE. Advance directives at end-of-life: nursing home resident preferences for artificial nutrition. J Am Med Dir Assoc 2007;8:224-8.

13 Weinick RM, Wilcox SR, Park ER, et al. Use of advance directives for nursing home residents in the emergency department. Am J Hosp Palliat Care 2008;25:179-83.

14 Miles SH, Koepp R, Weber EP. Advance end-of-life treatment planning. A research review. Arch Intern Med 1996;156:1062-8.

15 Pauls MA, Singer PA, Dubinsky I. Communicating advance directives from long-term care facilities to emergency departments. J Emerg Med 2001;21:83-9.

16 Hinders D. Advance directives: limitations to completion. Am J Hosp Palliat Care 2011;29:286-9.

17 Brown M. The law and practice associated with advance directives in Canada and Australia: similarities, differences and debates. J Law Med 2003;11:59-76.

18 Baker ME. Economic, political and ethnic influences on end-of-life decision-making: A decade in review. J Health Soc Policy 2002;14:27-39.

19 Bradley EH, Wetle T, Horwitz SM. The patient self-determination act and advance directive completion in nursing homes. Arch Fam Med 1998;7:417-23.

20 Orlander JD. Use of advance directives by health care workers and their families. South Med J 1999;92:481-4.

21 Daaleman TP, Williams CS, Preisser JS, et al. Advance care planning in nursing homes and assisted living communities. J Am Med Dir Assoc 2009;10:243-51.

22 Resnick HE, Schuur JD, Heineman J, et al. Advance directives in nursing home residents aged $>$ or $=65$ years: United States 2004. Am J Hosp Palliat Care 2008;25:476-82.

23 Yuen JK, Reid MC, Fetters MD, et al. Hospital Do-Not-Resuscitate orders: Why they have failed and how to fix them. J Gen Intern Med 2011;26:791-7.

24 Biola H, Sloane PD, Williams CS, et al. Preferences versus practice: life-sustaining treatments in last months of life in long-term care. J Am Med Dir Assoc 2010;11:42-51.

25 Toller CA, Budge MM. Compliance with and understanding of advance directives among trainee doctors in the United Kingdom. J Palliat Care 2006;22:141-6.

26 Bond CJ, Lowton K. Geriatricians' views of advance decisions and their use in clinical care in England: qualitative study. Age Ageing 2011;40:450-6.

27 Taylor D, Cameron PA. Advance care planning in Australia: overdue for improvement. Intern Med J 2002;32: 475-80.

28 Brown M, Grbich C, Maddocks I, et al. Documenting end of life decisions in residential aged care facilities in South Australia. ANZ J Pub Health 2005;29:85-90.

29 Mitchell G, Nicholson C, McDonald K, et al. Enhancing palliative care in rural Australia: the residential aged care setting. Aus J Primary Health 2011;17:95-101.

30 Lyon C. Advance care planning for residents in aged care facilities: what is best practice and how can evidence-based 
guidelines be implemented? Int J Evid Based Healthcare, 2007;5:450-7.

31 Chang E, Hancock K, Harrison K, et al. Palliative care for end-stage dementia: A discussion of the implications for education of health care professionals. Nurse Educ Today 2005;25:326-32.

32 Jeong SY, Higgins I, McMillan M. Advance care planning (ACP): The nurse as "broker" in residential aged care facilities. Contemp Nurse 2007;26:184-95.

33 Shanley C, Whitmore E, Khoo A, et al. Understanding how advance care planning is approached in the residential aged care setting: A continuum model of practice as an explanatory device. Australas J Ageing 2009;28:211-5.

34 Fernandes G. Implementation of best practice in advance care planning in an 'ageing in place' aged care facility. Int J Evid Based Healthc 2008;6:270-6.

35 Commonwealth of Australia. A National Health and Hospitals Network for Australia's Future: Delivering better health and better hospitals. 2010; Appendix C, 411-3. http://www.health. gov.au/internet/yourhealth/publishing.nsf/Content/ report-redbook/\$File/HRT_report3.pdf (accessed 20 Feb 2012).
36 Commonwealth of Australia. Supporting Australians to Live Well at the End of Life: National Palliative Care Strategy. 2010. http://www.health.gov.au/internet/main/publishing.nsf/Content/ 533C02453771A951CA256F190013683B/\$File/

NationalPalliativeCareStrategy.pdf (accessed 20 Feb 2012).

37 Silvester W, Blackford J, Strickland E, et al. Final Evaluation of the Community Implementation of the Respecting Patient Choices Program. http://www.health.gov.au/in...0Silvester\%20et \%20al\%20Submission\%20B.pdf (accessed 5 Jan 2012).

38 Commonwealth of Australia. A National Framework for Advance Directives. The Clinical, Technical and Ethical Principal Committee of the Australian Health Minister's Advisory Council, 2011. http://www.ahmac.gov.au/cms documents/AdvanceCareDirectives2011.pdf (accessed 10 Jun 2012).

39 Bezzina A. prevalence of advance care directives in aged care facilities in the Northern Illawarra. Emerg Med Aust 2009;21:379-85.

40 Schickedanz AD, Schillinger D, Landefeld S, et al. A clinical framework for improving the Advance Care Planning process: Start with patients' self-identified barriers. J Am Ger Soc 2009;57:31-9. 